\title{
ENGINEERING DESIGN OF INDUSTRIAL PRODUCTION OF GOLDEN-EYED LACEWINGS (CHRYSOPERLA CARNEA STEPH L.) IN PROGRAMS OF BIOLOGICAL PROTECTION OF PLANTS
}

\author{
Valentina Krutiakova $^{1}$, Igor Bespalov ${ }^{1}$, Volodymyr Bulgakov ${ }^{2}$, Dainis Viesturs ${ }^{3}$ \\ ${ }^{1}$ Engineering and Technology Institute "Biotechnica", Ukraine; \\ ${ }^{2}$ National University of Life and Environmental Sciences of Ukraine, Ukraine; \\ ${ }^{3}$ Latvia University of Life Sciences and Technologies, Latvia \\ semjons@apollo.lv
}

\begin{abstract}
Application of useful insects (including the golden-eyed lacewings) has great prospects in biological agriculture. Large-scale industrial cultivation of the golden-eyed lacewings is connected with the complexity of the technological process and equipment, as well as the need to combine the knowledge of several branches of science. The purpose of this research is to develop an efficient variant of the technological system, in which the industrial cultivation of the golden-eyed lacewing is implemented, defining the basic requirements for the structure of the relevant complex. The study was carried out on the basis of a new technological complex for the production of golden-eyed lacewings, which was created using methods adapted for entomological tasks of the system engineering design. The form and contents of the instrumental-operational scheme are proposed, which displays in space and time the work of all devices of the cultivation module. By means of the scheme and the selected periodicity an optimal ratio between the containers for cultivation is justified. This allows minimisation of the necessary number of devices, as well as development of appropriate schedules for the seasonal operation of the technological system. The use of this technique made it possible to work out the structure of a set of the basic equipment for cultivation of the golden-eyed lacewing on the sitotroga eggs ( 9.6 million eggs per cycle).
\end{abstract}

Keywords: golden-eyed lacewing,design, production, imago, larva, cocoon.

\section{Introduction}

Large-scale cultivation of useful arthropods is at the basis of augmentative biological control, which is an important component of ecological agriculture. One of the most efficient useful arthropods is the golden-eyed lacewing (Chrysoperla carnea L.), which feeds on various pests of agricultural crops [1-6]. In the world practice there are examples of creation of such production units, which ensure the output of tens of millions of insects per week. Difficulty of creating such industries is emphasised, which, first of all, is determined by the multidimensional nature of the tasks to be solved in various branches of science and technology, and, secondly, by the need for significant investments.

At the present time a scientific support for the large-scale insect cultivation is granted mainly in the field of technical entomology, as well as the emerging industrial entomology. Historically, the technologies of cultivation were developed in scientific laboratories of an entomological profile, and there specimens of the necessary equipment were created. After corresponding experimental and design work sets of equipment were created, which, instead of the apparatus for direct insect cultivation, simply reproduced the biotechnological parameters of the laboratory samples.

As the industry evolved, the sets of equipment became more complex in terms of both their diversity and the number of units. In fairly common sets of equipment for the cultivation of trichogrammes, bracon (Bracon hebetor L.), golden-eyed lacewing [4-6] there are used approximately a dozen basic equipments, and the number of containers, cuvettes, cassettes, etc. for insect cultivation is approaching a hundred. The equipment is supplied to the customer in the form of a set that is to be installed and started at the site of its operation. It is not detailed and practically covered in the operational documentation how the technological system of production is built on the basis of the equipment, including direct organisation of cultivation in dozens of containers.

Designing of industrial production units on their basis is an independent scientific and technical task; the methodology of its solution is well developed for other branches of industry. In particular, in a similar field of industrial microbiology, the necessary stage of creation of certain production is the technological or engineering design [7-10].

A technology and a set of equipment for breeding an entomophage of the golden-eyed lacewing was developed at the Technological Institute of Biotechnology (Ukraine).Their technical and economic indicators surpassed all the known analogy [11-14]. However, in the light of the above approaches to the design and organisation of industrial production, ways and methods were defined for 
further improvement of the equipment. At the end of the last century a new design ideology was formed, which was named system design [7;8]. Application of this methodology in the field of creation of entomological production units made it possible to conduct research and development of a new technological complex of industrial production of the golden-eyed lacewing. One of the results of the development is presented in this article.

The purpose of this research is to develop an efficient variant of the technological system, in which the industrial cultivation of the golden-eyed lacewing is implemented, defining the basic requirements for the structure of the relevant complex.

\section{Materials and methods}

The development of the technological process of industrial cultivation of the golden-eyed lacewing is carried out at the stage of an engineering (technological) design [12]. When adapting the general system design methodology to the engineering design of technological complexes for industrial cultivation of entomophages, two stages are distinguished:

- development of a set of functional devices;

- development of efficient variants of a technological system, defining the technical requirements for the relevant technological complexes.

The production process is designed on the basis of the new technological complex for the cultivation of the golden-eyed lacewing (further TCG), which was created at the first stage [13-14]. In these works the decisive role of the container design was justified in the technical solutions of the other equipment, as well as the technical and economic indicators of the complex, as a whole. The cultivation technology of the golden-eyed lacewing [9;10] is based on three types of containers (container-cassettes) of breeding (cultivation): for larvae (hereinafter referred to SL), for cocoons (hereinafter referred to as SK), for imago (hereinafter SI). In accordance with the developed model of technical and economic efficiency [11], the dimensions of the horizontal section of the working area of the containers were justified and selected for the cultivation of SI and SL $-250 \times 500 \mathrm{~mm}$. The specimens of the containers for the cultivation are shown in Fig. 1.
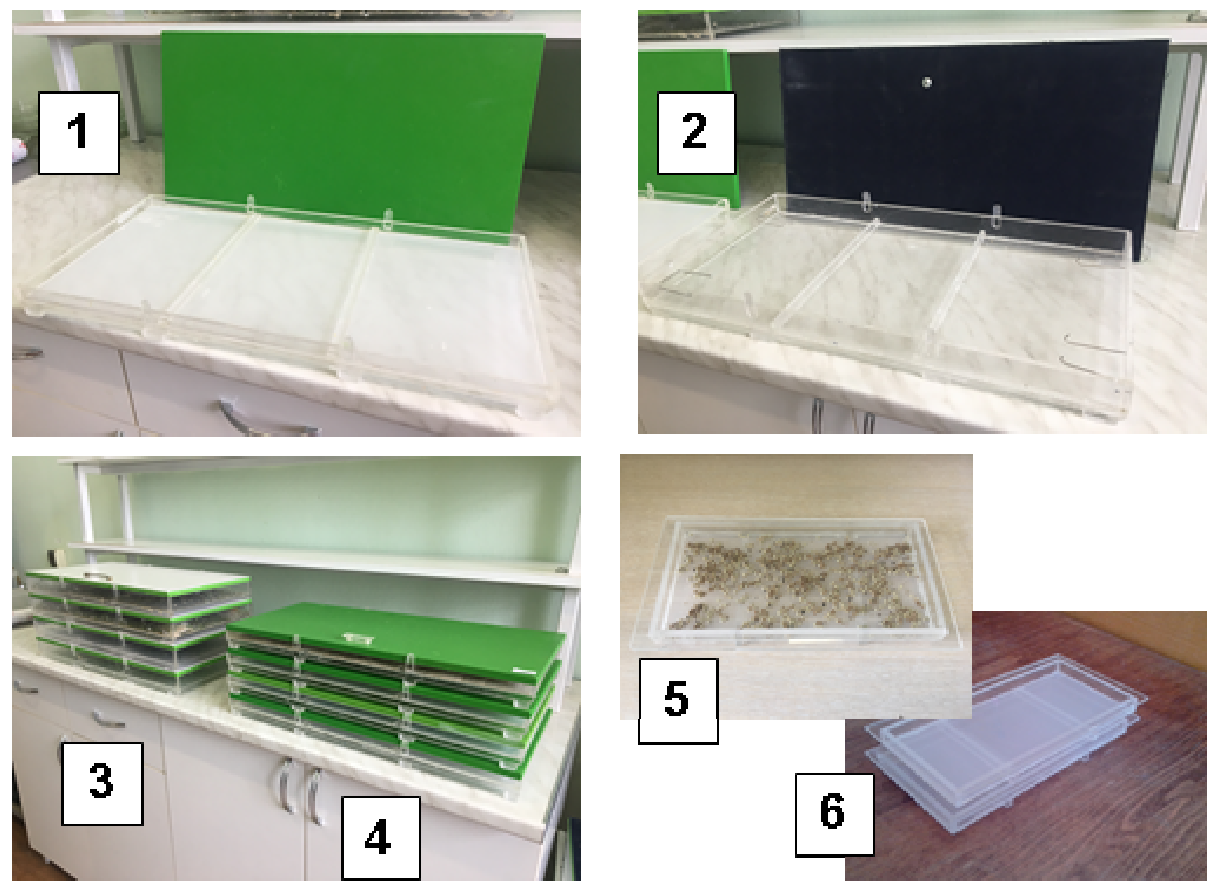

Fig. 1. Containers for cultivation of golden-eyed lacewing: 1 - for the larvae with a lid; 2 - for the imagos with a lid; 3 - an assembly of containers for the cultivation of the imagos (the adult (definitive) stage of individual development); 4 - an assembly of containers for the cultivation of larvae; 5 - for growing cocoons; 6 - an assembly of containers for growing cocoons 
In contrast to the development [3], they have twice larger working area, which reduced the cost of their production and the number of units in the complex.

The system of these containers for the cultivation, which forms in the general structure of the complex a so-called cultivation module, is the subject of research at the stage of the engineering design.

\section{Results and discussion}

The previously developed technological procedure for the cultivation of the golden-eyed lacewing actually describes the technological process that is carried out in single chain of the cultivation containers [12;13]. This conclusion applies also to the other regulations or technologies, known to us. The existing instrumental-operational schemes of the technological process are functional and reflect very conditionally in which device a certain technological operation takes place, and do not determine their number and interrelations at all. That is, in what sequence to work, for example, with 105 pieces of three types of containers [14] in time and space is left to the discretion of the production personnel.

Such a situation in the creation of large-scale cultivation technologies is observed in all publications, known to us. As a matter of fact, this testifies to methodological shortcomings of the technology of industrial production of insects, which should be based on a complete principal instrumental and technological operating scheme. The scheme should reflect in time all technological operations with all the basic devices of the cultivation module, in which insects are kept at different stages of ontogenesis.

To overcome this methodological disadvantage, the structure and form of the instrumentaloperational scheme were developed (Fig. 2). The scheme reflects in time and space the work of all the containers, in which the cultivation of the golden-eyed lacewings is carried out. The basic provision of the schemes is the concept of "a group" - as a combination of a certain number of containers or lids, in which insects of the same age and stage are located. All the technological operations with the elements of the group are performed simultaneously. In fact, the group is a conventional unit of technological processing and a conditional cage with a total working area.

Fig.1 $(3,4)$ show groups of four containers for the cultivation of the imagos and larvae, which are structurally fixed in the assemblies. The assemblies ensure convenient transportation of the containers and significantly reduce the technological area for their placement.

In our previous articles [13;14], a design of 3 types of cages with lids having optimal crosssection sizes of $25 \times 50 \mathrm{~cm}$ were considered, based on the basic ratio:

$$
1 \mathrm{SL} \rightarrow 2 \mathrm{SK} \rightarrow 1 \mathrm{SI} \rightarrow 1 \mathrm{~K},
$$

which reflects the material balance of the number of insects at different stages of ontogenesis in each, that is, one cage of larvae SL gives the required number of cocoons to load two cages of cocoons SK, the imago of which is loaded into one cage of the imago SI. SK has a cross section of $25 \times 12.5 \mathrm{~cm}$ to ensure easy overloading of the imago. SI produces one lid K with eggs daily, that, for a period of 49 days, gives about 300 thousand eggs.Each lid is placed on the SI for one day, then two days on the rack for incubation. The eggs are collected daily in one. One Petri dish (PD) holds up to 200 thousand eggs, this amount is collected from 32 lids.

If we take, for example, a group of 4 simultaneously working SL, then they will ensure the loading of 4 SI, that is, one GSL group ensures the work of one GSI group. This allows using this scheme for complexes of various efficiency, which is determined by the number of containers in the group.

Description of the operation of the scheme (Fig. 2): On the first day the eggs of the golden-eyed lacewings are moved into Group GSL 1; feeding of the hatched larvae is carried out by the sitotroga eggs; on the 15th day the larvae turn into cocoons. The cocoons are transferred to the GSK containers, where they are kept for 8 days before the imagos fly out. After 20-23 days the imagos are carried to the imago containers, where their development takes place. After 26 days regular egg laying starts on the GK lids. Lids with the GK 1 eggs are removed every day and replaced with the GK 2 lids; then the GK 2 is replaced with the GK3, and so on. Then the eggs on the lids go through 2 days of incubation, and on the 28th day they are removed from the lid and collected in the PPP dishes for further use or 
storage. The process of collecting eggs in the SI continues 49 days by daily replacement of the dishes, for which each SI must have 3 dishes. Thus, the first cycle of the GSL 1-GSI 1 operation is implemented.

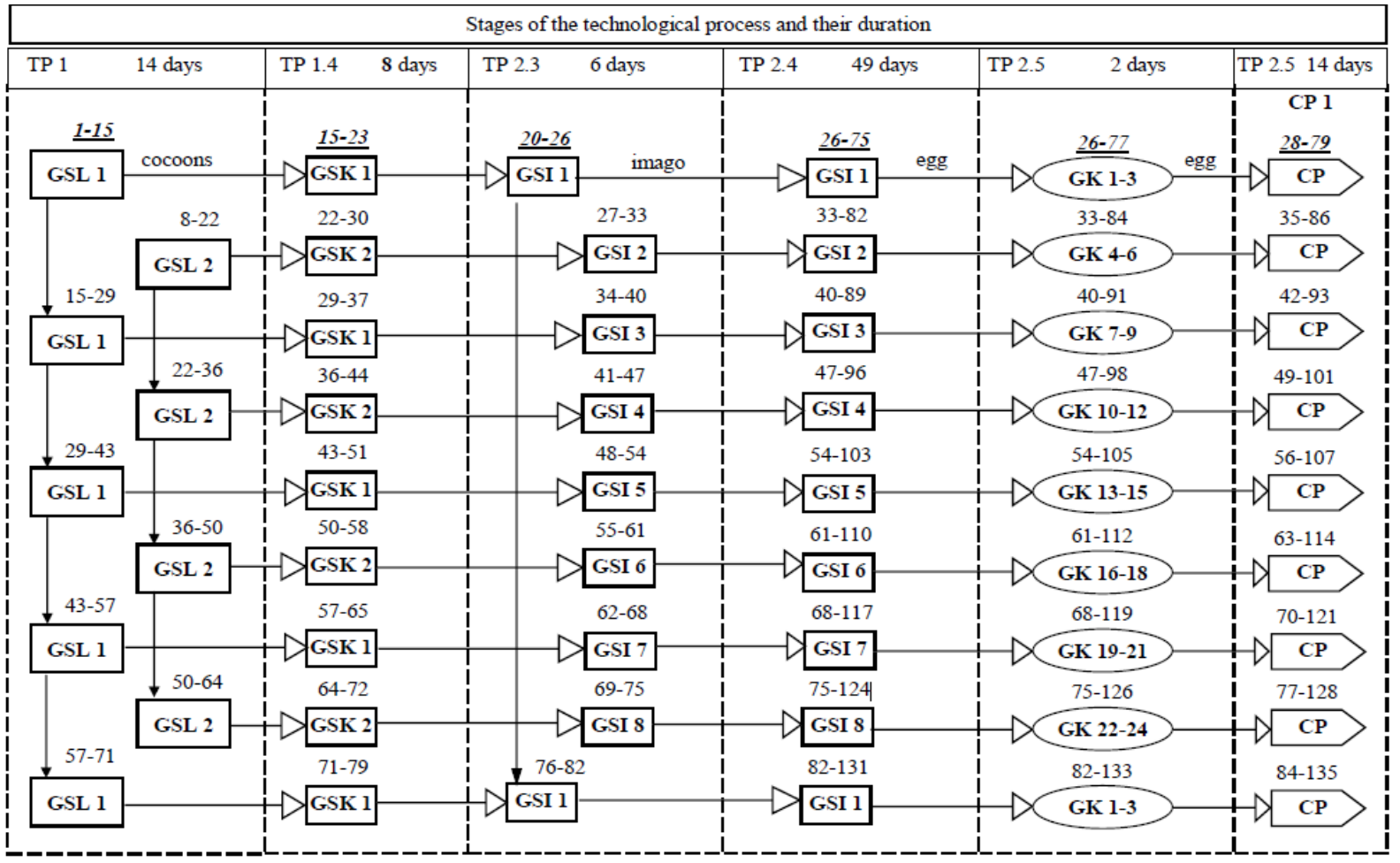

Fig. 2. Scheme of instrumental-operational module for cultivation systems of golden eyed

lacewings: TP1 - feeding of the larvae, obtaining cocoons, TP 1.4 - keeping the cocoons before the

imagos fly out, TP 2.3 - filling the containers, the development of the imagos, TP 2.4 - collecting eggs and feeding the imagos, TP 2.5 - incubation and collection of eggs, TP 3 - storage and use of the eggs. The rectangles designate groups: GSL 1,2 - group of containers for growing larvae number 1, 2;

GSK 1, 2 - group of containers for growing cocoons; GSI $1 \ldots 8$ - group of containers for growing imagos number $1 \ldots 8$. The ovals - groups of lids of the imago containers GK $1 \ldots 24$ on which eggs are laid; PD - Petri dishes with a one-day collection of eggs from a group of lids;

$\rightarrow-$ The output product from the device; $\longrightarrow-$ Moving the device to the next cycle of work.

Above the figure of each group of devices there are numbers that reflect the date of the beginning and the end of the work in days. The reference starts from the beginning of the cycle of the complex.

On the $15^{\text {th }}$ day the GSL 1 is freed from the cocoons, it is cleaned, and its second cycle begins. In industrial production with a significant amount of manual labour (all technological operations are carried out by man) organisation of the work in time is extremely important. Analysis of the variants of organisation of operations was made while implementing a fairly long cycle of 79 days with each group. It was found in an experimental way that the simplest variant is to organise the cycles with weekly intervals. In this case a week after the start of the cycle with the GSL 1 , on the $8^{\text {th }}$ day the cycle begins with a new GSL 2 and GSI 2. As it is evident from Fig. 3, this provides a possibility for two groups - GSL 1 and GSL 2 - to start functioning of eight groups of containers of the imago GSI 1 to GSI 8 with the corresponding 24 groups of the lids GK 1-GK 24.

Thus, an optimal ratio between the groups of containers and lids is determined, which ensures their maximum loading during the entire cycle and, consequently, a minimum number of units for a given efficiency:

$$
2 \mathrm{GSL} \rightarrow 8 \mathrm{GSI} \rightarrow 24 \mathrm{GK},
$$

The size of the group is determined by the amount of the SL; one container for the larvae produces cocoons in the amount needed for loading one cage of the imagos; one SI requires 3 lids $\mathrm{K}$ for laying and incubating eggs. In accordance with these ratios, the necessary modifications of the 
TKZ complexes are designed, which determine the number of the basic devices - the containers of the cultivation module in order to ensure the preset capacity of the designed production.

For example, the most economically appropriate for the common biolaboratories in Ukraine is a modification of the TKZ-4 complex with a group size of four cages, the specification of which is given in Table 1 .

Table 1

Specification of the complex TKZ-4

\begin{tabular}{|c|l|c|}
\hline Designation & \multicolumn{1}{|c|}{ Name of the equipment } & $\begin{array}{c}\text { Amount, } \\
\text { pieces }\end{array}$ \\
\hline SL & The larva container & 8 \\
\hline SK & The cocoon container & 16 \\
\hline SI & The imago container & 32 \\
\hline K & Lids of the imago cage & 96 \\
\hline PD & The Petri dish & 14 \\
\hline
\end{tabular}

Estimation of the efficiency of the complex TKZ-4 has been made. By its efficiency one SI produces an average of 300 thousand golden-eyed lacewing eggs per cycle of work, which are removed from the lids. By the selected duration of the egg collection in 49 days, the average daily amount of eggs, collected from one lid, is 6123 thousand eggs per day. During one cycle of operation of a group of the containers GSI, one can obtain 392 groups of the GK lids, and from two cycles during a season -784 pcs.

The dynamics of the egg production in a season with one or two cycles is presented in the graphs of Fig. 3, from where the main indicators of the TKZ -4 complex were calculated:

- efficiency per season from one cycle - 9.6 million eggs, from two cycles - 19.2 million eggs;

- duration of the production of the eggs: one cycle - 98 days, two cycles -147 days;

- average daily productivity, one cycle -0.098 million eggs a day, two cycles -0.131 million eggs per day.

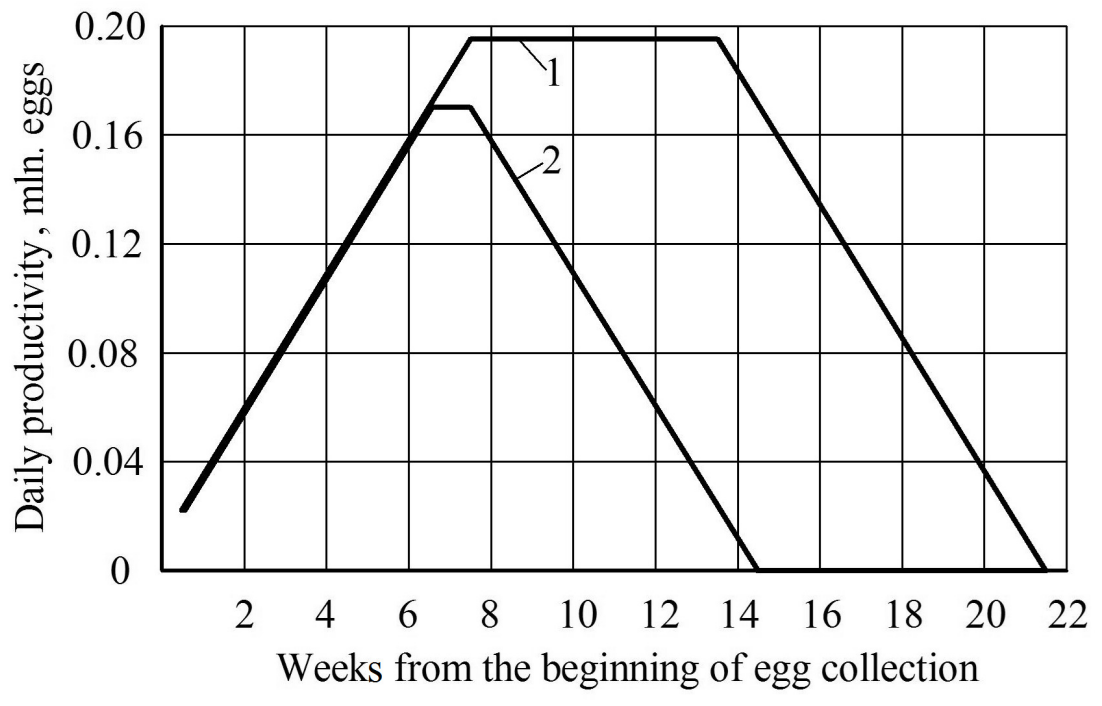

Fig. 3. Daily efficiency of technological complex of golden-eyed lacewing cultivation complex:

$$
1 \text { - two cycles; } 2 \text { - one cycle }
$$

The approaches and procedures proposed above may be viewed as a methodology for the analysis and synthesis of a particular production process using an instrumental-operational scheme for groups of containers and lids. This methodology allows synthesis of various production variants, including with a minimum number of containers. It is also possible to change the starting interval of the larva containers from a weekly to another one, more appropriate for a particular customer. 


\section{Conclusions}

A methodology for the engineering design of the cultivations process of entomophages has been developed using as an example the golden-eyed lacewings by means of the proposed concepts of a group and an instrumental-operational scheme, reflecting the work of each device of the cultivation module in time and space. This makes it possible to minimise the required number of devices in the technological complex, as well as develop appropriate schedules for the seasonal operation of the complex.

\section{References}

[1] Lenteren J.C. The state of commercial augmentative biological control: plenty of natural enemies, but a frustrating lack of uptake. Biological Control, Vol. 57, No 1, 2012, pp. 1-20.

[2] Norman C. Leppla, Juan A. Morales-Ramos, David I. Shapiro-IlanM. Guadalupe Rojas. Mass Production of Beneficial Organisms. Invertebrates and Entomopathogens. Elsevier Inc., 2014.

[3] Zaki F.N., Gesraha M.A. Production of the green lacewing Chrysoperla caranea (Steph.) (Neuropt., Chrysopidae) reared on semi-artificial diet based on the algae, Chlorella vulgaris. Journal of Applied Entomology. Vol. 125, Issue 1-2, 2001, pp. 97-98

[4] Papaj D.R., Prokopy R.J. Ecological and evolutionary aspects of learning in phytophagous insects, Annual review of entomology, Vol. 34, 1989, pp. 315-350

[5] Timms J.E., Oliver T.H., Straw N.A., Leather S.R. The effects of host plant on the coccinellid functional respons: Is the conifer specialist Aphidecta obliterata L.) (Coleoptera: Coccinellidae) better adapted to spruce than the generalist Adalia bipunctata (L.), Biological Control, 47 (3), 2008, pp. 273-281.

[6] Nitharwal M.,Kumawat K.C., Choudhary M., Jat R.G. Influence of biorational and conventional insecticides on the population of chrysoperla carnea (steph.) In green gram, vigna radiata (linn.) In semi-arid conditions. Biopesticides International, Vol. 9, Issue 1, 2013, pp. 83-87

[7] Кантере В.М., Мосичев М.С., Дорошенко М.И., Калунянц К.А., Брысин А.М. Основы проектирования предприятий микробиологической промышленности. (Fundamentals of designing the enterprises of the microbiological industry), Moscow, 1990, 304 p. (In Russian)

[8] Грачева И.М., Калунянц К.А., Кестельман В.Н., Петрова Н.М. Технологическое проектирование предприятий ферментной промышленности (Technological designing of enterprises of the fermentation industry), Moscow, 1973, 287 p. (In Russian)

[9] Jones J.C. "Design Methods", John Wiley and Sons Ltd., 1982.

[10] ХорошевА.Н. Основысистемногопроектированиятехническихобъектов(Fundamentals of system engineering of technical objects), Moscow, 2011, 125 p. (In Russian)

[11] Шейкин Б.М., Бельченко В.М., Беспалов И.Н., Шейкина Е.Б. Биотехнологические системы в промышленной энтомологии (Biotechnological systems in industrial entomology). Сборник. научныхтрудов «Защитарастений» (Proceedings "Plantrotection”), Несвиж, Беларусь, № 38, 2014, pp. 245-250 (In Russian)

[12] Krutyakova V. Effective Technological Equipment for Mass Production of Entomophagous Insects and Mites Used for Biological Control. Journal of Agricultural Science and Technology, No 7, 2017, pp. 179-186.

[13] Bespalov I., Hodorchuk V. Fundamentals of engineering design of technological complexes for industrial production of entomophages. Materials of the International Scientific Conference "Plant Protection in Traditional and Ecological Agriculture". Institute of Genetics, Physiology and Plant Protection, Chisinau, 2018, pp.163-167.

[14]Сапожникова М., Білоусов Ю., Бельченко М. Технологія імаго звичайної золотоочки Chrysoperla affinis Steph. (The imago technology of the common golden gold-eye lacewing Chrysoperla affinis Steph). Вісник аграрної науки Південного регіону: міжвідомчий тематичний науковий збірник (Journal of Agrarian Science of the Southern Region of Ukraine), No 12, 2012, Одесса, pp. 128-138. (In Ukrainian). 